Special issue of the 3rd International Conference on Computational and Experimental Science and Engineering (ICCESEN 2016)

\title{
Investigation of the Crash Boxes Light Weighting with Syntactic Foams by the Finite Element Analysis
}

\author{
H. ÖZER ${ }^{a}, Y$. CAN ${ }^{b, *}$ AND M. YAZICI ${ }^{a}$ \\ ${ }^{a}$ Department of Automotive Engineering, Faculty of Engineering, Uludag University, Bursa, Turkey \\ ${ }^{b}$ R\&D Center, Oyak-Renault Co. Inc., Bursa, Turkey
}

\begin{abstract}
Light-weighting is a new scope in the automotive industry to accommodate new emission regulations. The parts produced with conventional metallic materials are replaced with parts produced by using light weight or high strength materials, to obtain light weighted equivalents of the same strength. Foam core sandwich structures, high strength steels, composite materials are the most used alternative materials. Syntactic foams that show outstanding performance in case of high-speed collisions have an excellent utility as energy absorbers in vehicle crash boxes. Syntactic foams are modeled in crash boxes at various filling rates and filling patterns in the context of this study. As results of the FEM analyses, it is observed that syntactic foams have excellent crash performance, as well as weight-reducing effect in vehicle crash boxes.
\end{abstract}

DOI: 10.12693/APhysPolA.132.734

PACS/topics: 02.70.Dh, 62.20.- x, 61.41.+e

\section{Introduction}

Syntactic foam materials are produced by adding microbubbles into a matrix material. Due to the contribution of the microbubbles, matrix materials obtain low density, low heat conductance, low moisture absorbance, and closed cell foam structures. Syntactic foams provide lightness in the structures in which they are used. With these features, the syntactic foam materials are used in aviation, space and marine industries. In these structures, usually empty glass micro balloons are used as cell material and epoxy, polyurethane, and metal materials are used as matrix material [1-5]. The syntactic foams have high compression strength under static and dynamic loads [6-11]. For that reason, they are excellent candidate core materials for sandwich structures with composite face sheets [12-15]. Syntactic foams show strain rate sensitivity, depending on the micro glass bubbles percentage. Yazici presented a syntactic foam by adding micro glass bubbles and silicone rubber into polyurethane resin and obtained dynamic compression strength nine times higher than that of the quasi-static case [5].

Shunmugasamy et al. observed that with the increase of the strain rate, compression strength also increases [16]. When the adequately high loads are applied to the syntactic foams, some damages, such as micro glass bubbles collapses, and glass bubbles/matrix interface cracks, can occur. Therefore, researchers have developed a higher strength syntactic foams by reinforcing the matrix material with short and long fibers $[17,18]$.

In compliance with the new official low $\mathrm{CO}_{2}$ emission regulations for the automotive industry, comprehensive studies are conducted to decrease the weight of

*corresponding author; e-mail: yucel.can@renault.com the vehicles and to increase safety [19-21]. The displacement of the crash boxes in the direction of the vehicle body, which will happen in a frontal crash of a vehicle, presents great importance, regarding the safety of the driver and of the passengers. Therefore, at the instant of the collision, the loads coming from the bumper towards the car body are absorbed by the crash boxes at certain levels. For this reason, crash boxes are developed using the highly attenuating materials. The researchers have experimented with the foam materials by filling the empty volumes in the impacts absorbers, and the strength values of the crash elements were improved $[20,21]$. The syntactic foam materials can be used in the vehicle crash boxes because of their high energy absorbing properties besides their light weight [22].

In this study, the aluminum crash boxes are modeled by filling the empty volumes with syntactic foam materials and finite elements analyses are performed. Micro glass bubble/epoxy syntactic foam characteristics were taken from the literature data [11], and Johnson-Cook parameters were calculated. Thus, in the finite element analyses, crash box impact energy absorption levels with the various syntactic foam filling configurations are observed. Moreover, to decrease the reaction forces between the car body and crash box, various syntactic foam filling configurations are developed, and the optimum case is presented.

\section{Materials and methods}

The crash boxes transform the kinetic energy into another form of energy at the instant of the crash. Therefore, the impact absorbers are manufactured from materials with high absorption specifications and geometries. It is considered that using the syntactic foam materials which show high performance under sudden impacts and dynamic weights in the crash boxes in the automotive industry can be an alternative to the conventional crash box materials. 


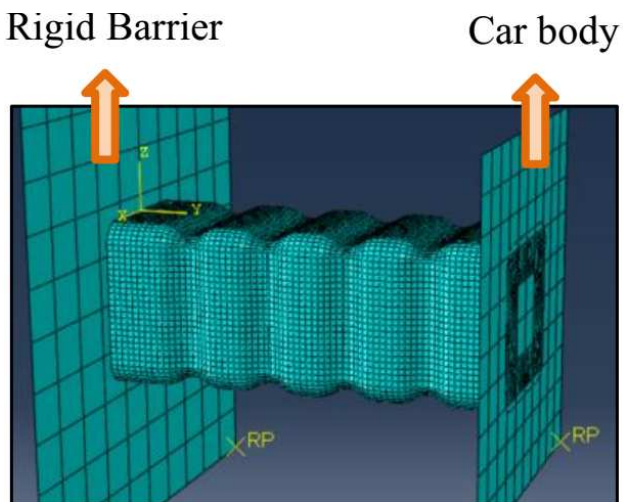

Fig. 1. Crash boxes.
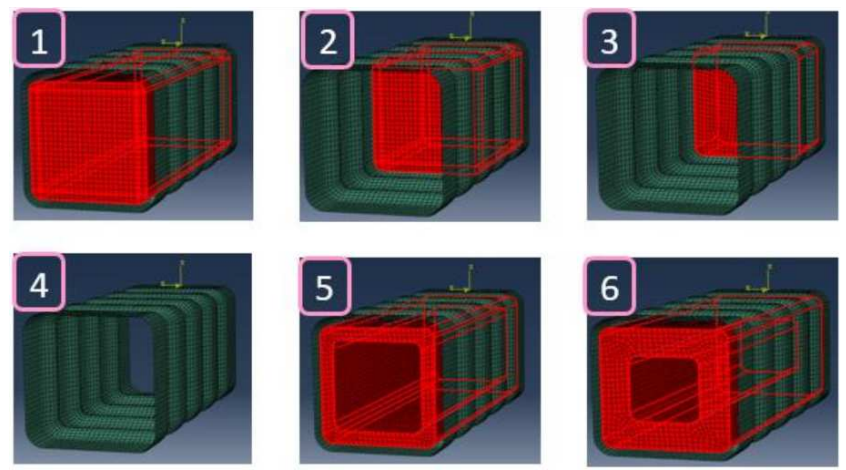

Fig. 2. Crash boxes models for six considered cases.

In this context, by modeling syntactic foam materials placed into aluminum crash boxes with dimensions of $70 \times 70 \times 200 \mathrm{~mm}^{3}$, analyses were made for six different cases, which are shown in Figs. 1 and 2. The syntactic foam material is filling the crash boxe entirely in the $1^{\text {st }}$ case, $1 / 2$ in the $2^{\text {nd }}$ case and $1 / 4$ in the $3^{\text {rd }}$ case. For the $4^{\text {th }}$ case, the model was created without syntactic foam while the $5^{\text {th }}$ case was modeled with $8 \mathrm{~mm}$ thick wall of syntactic foam. For the $6^{\text {th }}$ case, the wall thickness of syntactic foam was set to $16 \mathrm{~mm}$.
TABLE I

Parameters for the Al6061 Johnson-Cook plasticity model [23].

\begin{tabular}{c|c|c|c|c|c|c|c|c}
\hline \hline Materials & $\begin{array}{c}\mathrm{A} \\
{[\mathrm{MPa}]}\end{array}$ & $\begin{array}{c}\mathrm{B} \\
{[\mathrm{MPa}]}\end{array}$ & $\mathrm{n}$ & $\begin{array}{c}Q_{\text {melt }} \\
{[\mathrm{K}]}\end{array}$ & $\begin{array}{c}Q_{\text {trans. }} \\
{[\mathrm{K}]}\end{array}$ & $\mathrm{m}$ & $\mathrm{C}$ & $\begin{array}{c}\dot{\varepsilon}_{0} \\
{[1 / \mathrm{s}]}\end{array}$ \\
\hline Al 6061 & 324.1 & 113.8 & 0.42 & 925 & 293.2 & 1.34 & 0.002 & 1
\end{tabular}

TABLE II

Parameters for the Al6061 Johnson-Cook dynamic failure model [23].

\begin{tabular}{c|c|c|c|c|c}
\hline \hline Materials & $d_{2}$ & $d_{2}$ & $d_{3}$ & $d_{4}$ & $d_{5}$ \\
\hline Al 6061 & -0.77 & 1.45 & 0.47 & 0.0 & 1.6
\end{tabular}

TABLE III

Parameters for the syntactic foam elastic model [11].

\begin{tabular}{c|c|c|c}
\hline \hline Materials & $\begin{array}{c}\text { Density } \\
{\left[\mathrm{g} / \mathrm{cm}^{3}\right]}\end{array}$ & $\begin{array}{c}\text { Young's modulus } \\
{[\mathrm{MPa}]}\end{array}$ & $\begin{array}{c}\text { Poisson's } \\
\text { ratio }\end{array}$ \\
\hline $\begin{array}{c}\text { Syntactic } \\
\text { foams }\end{array}$ & 0.3 & 1650 & 0.2
\end{tabular}

TABLE IV

Parameters for the syntactic foams Johnson-Cook plasticity model [11].

\begin{tabular}{c|c|c|c|c|c|c}
\hline \hline Materials & $\begin{array}{c}\mathrm{A} \\
{[\mathrm{MPa}]}\end{array}$ & $\begin{array}{c}\mathrm{B} \\
{[\mathrm{MPa}]}\end{array}$ & $\mathrm{n}$ & $\mathrm{m}$ & $\mathrm{C}$ & $\begin{array}{c}\dot{\varepsilon}_{0} \\
{[1 / \mathrm{s}]}\end{array}$ \\
\hline $\begin{array}{c}\text { Syntactic } \\
\text { foams }\end{array}$ & 15 & 0.01 & 0.0001 & & 0.105 & 3500
\end{tabular}

Parameters for the Al6061 Johnson-Cook plasticity model and Johnson-Cook dynamic failure model are given in Table I and Table II [23]. Parameters for the syntactic foam elastic model and Johnson-Cook plasticity model are shown in Tables III and IV, respectively. Table $\mathrm{V}$ demonstrates the mass of syntactic foam materials for the crash box at different conditions.

\section{TABLE V}

Foam geometries and configurations used in finite element analysis models.

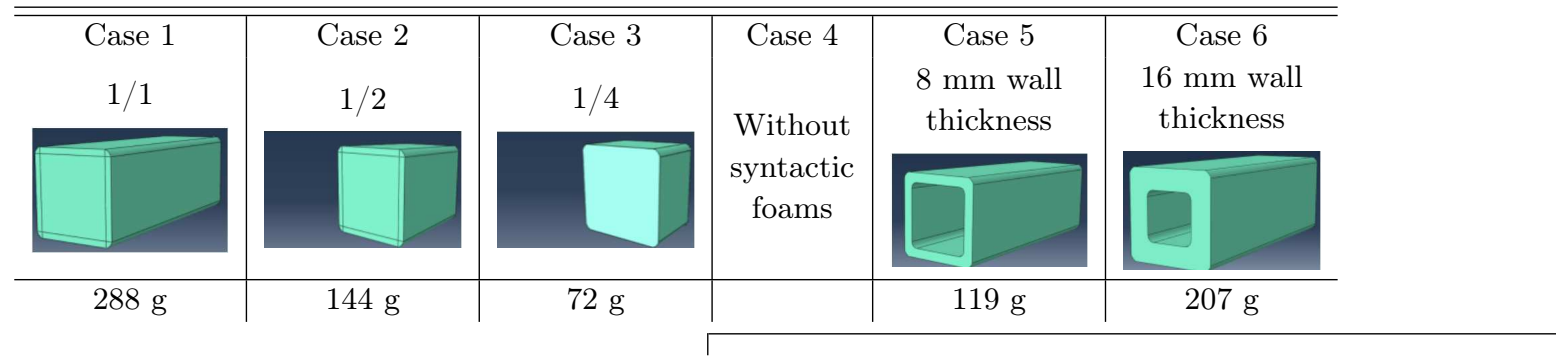

\section{Finite element analysis}

The mesh structure of modeled crash boxes was created with HyperMesh for all six different cases. The model boundary conditions and analysis conditions of crash boxes have been set up by Abaqus/Explicit 6.12.1 FEA software. In the aluminum crash box, 7376 linear 
quadrilateral elements were utilized. According to different shape and size of foam fillers, from 10816 to 41540 linear hexahedral elements for foam infill $\mathrm{FE}$ models were used. The linear quadrilateral elements and linear hexahedral elements were S4R and C3D8R types respectively of Abaqus software [24]. A rigid wall, which has
$64 \mathrm{~km} / \mathrm{h}$ initial velocity was put in contact with the crash boxes during $5 \mathrm{~ms}$ to simulate a frontal collision between a vehicle and the rigid wall. During the collision event, the vehicle crash box displacement, shape changes, and energy damping behavior were investigated (Fig. 3).
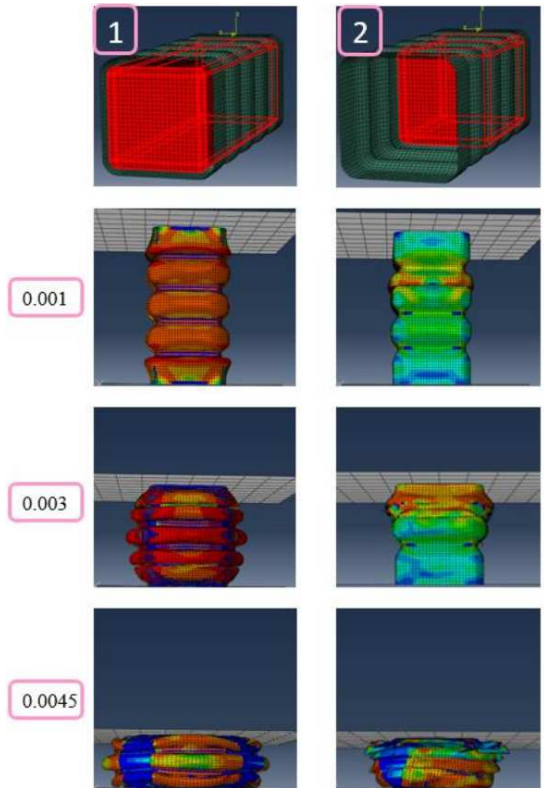
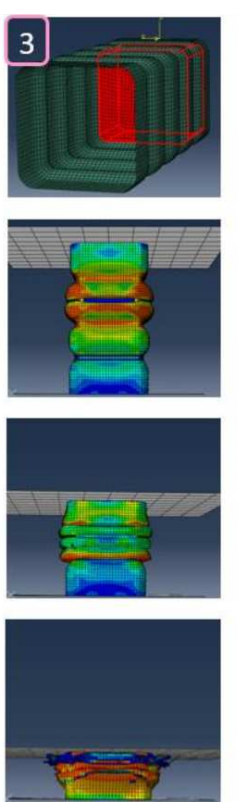
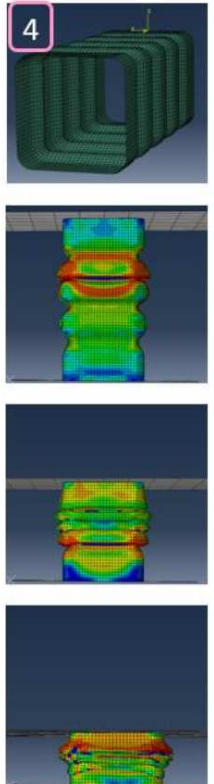
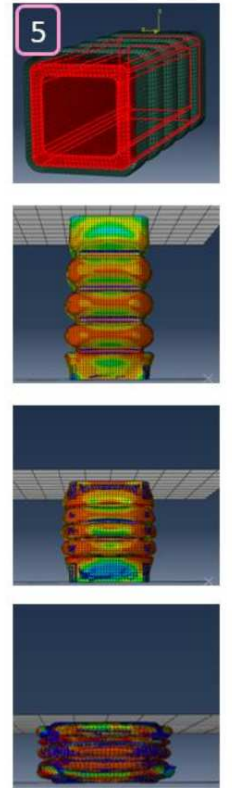
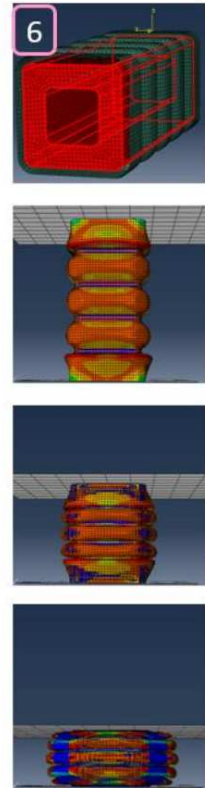

Fig. 3. Deformation of the crash boxes at 1, 3 and $4.5 \mathrm{~ms}$ time scales.

The modeling of the crash boxes internal volume with syntactic foam material in different cases has shown that the displacement values are not equal to each other. As can be seen in Fig. 4, with the increase of the foam ratio in the crash boxes, the displacement values decrease. That means the transferred energy from the crash boxes to the car body is affected by the syntactic foam filling configuration and ratio.

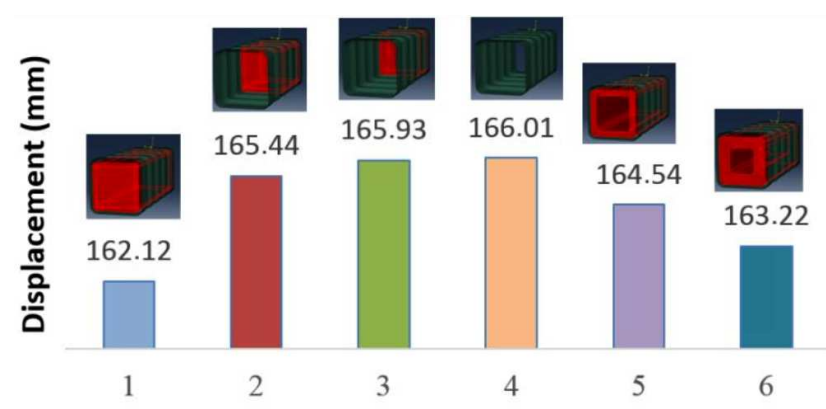

Fig. 4. Maximum displacements for all considered cases.

The desired reaction force generated in the vehicle during the crash should be small, regarding passenger and driver safety. Figure 5 shows time-dependent variations of the reaction force, acting on the crash boxes, for different designed cases. When $\mathrm{Al}$ crash boxes are modeled fully filled with syntactic foam material (Case 1), there is a very high initial reaction force. In the Case $2(1 / 2$ foam filler) and Case 3 (1/4 foam filler), the observed crash event has two different characters. From the beginning of the rigid wall-crash box contact to the frontal surface of foam block the reaction forces were at very low level. After the foam fillers were involved into the crash event, the reaction forces increased abruptly.

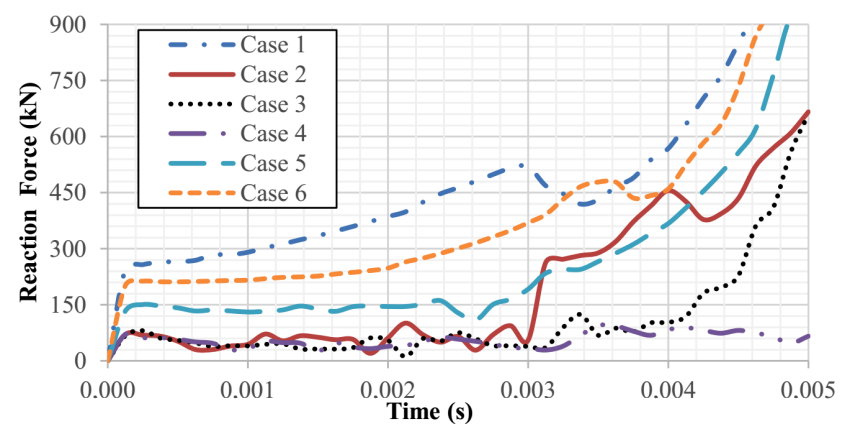

Fig. 5. Car body and crash box reaction force variation for all crash box configurations, as function of collision time.

Impact load of crash box, depending on elastic and plastic compression deformation during a crash event is shown in Fig. 6. The areas under the curves in Fig. 6, demonstrate absorbed energy for each of the designed crash boxes. The low energy absorption capability of the Case 2 and Case 3, compared to the other crash box designs, is evident from Fig. 6. 


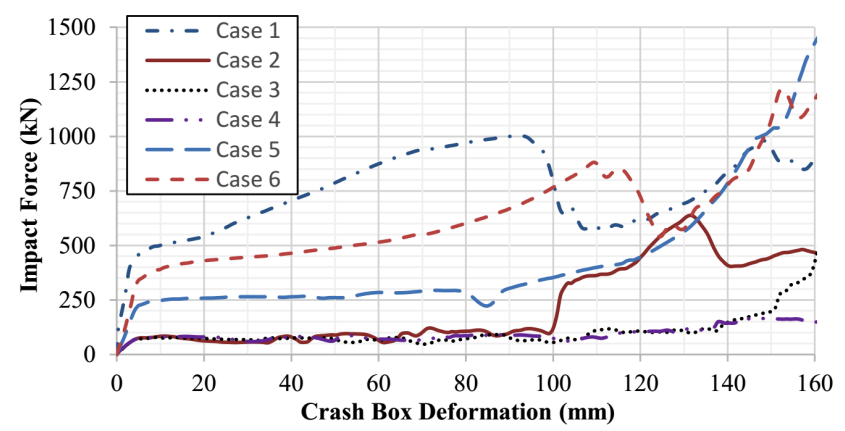

Fig. 6. Impact load and crash box deformation variations during a crash event.

In the crash box designs of Case 5 and Case 6 , the syntactic foam infill was positioned inside the crash boxes and had the wall thickness of $8 \mathrm{~mm}$ and $16 \mathrm{~mm}$. In these crash box configurations, the obtained reaction forces were higher than those in the Case 2, Case 3 and Case 4 , but they show higher impact energy absorption (see Fig. 6).

In Case 4, there is no syntactic foam filler inside the crash box. It shows the lowest rigidity up to the full collapse. The absorbed energy in this case was also the smallest. In Case 1 syntactic foam was completely filling the crash box. It shows the most rigid crash box behavior, compared to the other crash box cases. It has also transferred the largest impact force to the vehicle body. In all cases except Case 4, towards the end of the crash, the crash boxes became rigid forms by the syntactic foam densification.

\section{Conclusions}

During the crash, the syntactic foam material inside the crash box is utilized to increase the amount of the total energy absorption by converting it into another energy form. In all cases with syntactic foam filling, at the beginning of collision high reaction forces can occur. In the axial, partially filled crash box cases, instantaneous reaction forces are seen after the syntactic foam filler blocks are involved into the crash event. Optimum energy absorption and initial reaction force performance are obtained in the lateral side syntactic foam filled designs. It can be concluded that lateral sides foam filling of the crash boxes show better crash energy absorption properties than axial filling. Moreover, foam additions in the crash box do not significantly effect the total weight, but the impact energy absorption of the system is considerably improved.

\section{References}

[1] H. Geng, J. Liu, A. Guo, S. Ren, X. Xu, S. Liu, Mater. Des. 95, 32 (2016).

[2] R. Huang, P. Li, Compos.: Part B 78, 401 (2015).

[3] C. Swetha, R. Kumar, Mater. Des. 32, 4152 (2011).

[4] L. Peroni, P. Scapin, M. Avalle, J. Weise, D. Lehmhus, Mater. Sci. Eng. A 552, 364 (2012).

[5] M. Yazıc1, Acta Phys. Pol. A 129, 613 (2016).

[6] E. Zegeye, A.K. Ghamsari, E. Woldesenbet, Compos.: Part B 60, 268 (2014).

[7] K. Myers, B. Katona, P. Cortes, I.N. Orbulov, Compos.: Part A 79, 82 (2015).

[8] D. Lehmhus, J.Weise, J. Baumeister, L. Peroni, M. Scapin, C. Fichera, M. Avalle, M. Busse, Procedia Mater. Sci. 4, 383 (2014).

[9] N. Gupta, V.C. Shunmugasamy, Mater. Sci. Eng. A 528, 7596 (2011).

[10] Ph. Viot, K. Shankar, D. Bernard, Compos. Struct. 86, 314 (2008).

[11] P. Li, N. Petrinic, C.R. Siviour, R. Froud, J.M. Reed, Mater. Sci. Eng. A 515, 19 (2009).

[12] S. Eksi, K.Genel, Acta Phys. Pol. A 128, B-59 (2015).

[13] N. Ozsoy, M. Ozsoy, A. Mimaroglu, Acta Phys. Pol. A 128, B-55 (2015).

[14] N. Ozsoy, M. Ozsoy, A. Mimaroglu, Acta Phys. Pol. A 130, 297 (2016).

[15] I.K. Yilmazcoban, S. Doner, Acta Phys. Pol. A $\mathbf{1 3 0}$ 342 (2016).

[16] V.C. Shunmugasamy, N. Gupta, N.Q. Nguyen, P.G. Coelho, Mater. Sci. Eng. A 527, 6166 (2010).

[17] M. Colloca, N. Gupta, M. Porfiri, Compos.: Part B 44, 584 (2013).

[18] N.Q. Nquyen, N. Gupta, Mater. Sci. Eng. A 527, 6422 (2010).

[19] M. Yazıcı, H. Güçlü, I. Karen, I.K. Kandirmis, S. Malkoç, Ö.F. Buyukluoglu, Acta Phys. Pol. A 130, 262 (2016).

[20] H. Lin, H. Luo, W. Huang, X. Zhang, G. Yao, J. Mater. Proc. Technol. 230, 35 (2016).

[21] A.K. Toksoy, M. Güden, Thin-Walled Struct. 48, $482(2010)$.

[22] H. Özer, Y. Can, H. Güçlü, İ. Karen, M. Yazıcı, in: 8th Automotive Technologies Congress (Otekon 2016), 23-24 May, Bursa, Turkey 2016, p. 565.

[23] B.M. Corbett, Int. J. Impact Eng. 33, 431 (2006).

[24] ABAQUS, ABAQUS Analysis User's Manual, ver. 6.12, Dassault Systčmes Simulia Corp., Providence, USA 2012. 